Pragmatism and Psychologism

\title{
Security as Completeness
}

A Peircean Semiotic Reading of the Psychology of Attachment

\section{Matteo Santarelli}

\section{(2) OpenEdition}

\section{Journals}

Electronic version

URL: http://journals.openedition.org/ejpap/1009

DOI: 10.4000/ejpap.1009

ISSN: 2036-4091

Publisher

Associazione Pragma

Electronic reference

Matteo Santarelli, «Security as Completeness », European Journal of Pragmatism and American

Philosophy [Online], IX-1 | 2017, Online since 22 July 2017, connection on 12 June 2020. URL : http:// journals.openedition.org/ejpap/1009; DOI : https://doi.org/10.4000/ejpap.1009

This text was automatically generated on 12 June 2020 .

\section{(c) $(1) \odot$}

Author retains copyright and grants the European Journal of Pragmatism and American Philosophy right of first publication with the work simultaneously licensed under a Creative Commons AttributionNonCommercial-NoDerivatives 4.0 International License. 


\title{
Security as Completeness
}

\author{
A Peircean Semiotic Reading of the Psychology of Attachment
}

\author{
Matteo Santarelli
}

\section{Introduction: Peirce's Antipsychologism}

1 The psychologism vs. anti-psychologism debate is comprised of two contrasting epistemological and philosophical standpoints. From an anti-psychologist standpoint, psychologism consists of confusion between the domain of logic and the domain of psychology, which should properly remain separated. The resulting confusion is considered to have damaging epistemological consequences. Therefore, every intrusion of psychological elements into logic should be condemned as an instance of psychologism. On the other hand, psychologism maintains that the entanglement between psychological processes and logic is inescapable. It is impossible to account for the rules of logic without making use of psychological terminology.

2 Charles Sanders Peirce often explicitly endorsed an ant-psychologist standpoint. In contrast to John Stuart Mill, he refused any attempt to ground logic in psychology. He considered the two as being two different kinds of disciplines. Logic is a normative science, devoted to establishing valid laws of inference, among other things; psychology is conceived as an experimental, descriptive (Hookway 2012: 90) science, "concerned principally with explaining the affective, volitional, and cognitive processes and dispositions of human and other organisms" (Colapietro 2003: 164).

3 From an epistemological point of view, Peirce's antipsychologism is grounded in his long standing criticism of introspectionism. Starting from his early anti-cartesian essays, Peirce refused to grant any epistemological privilege to first person introspectionist approaches. On the contrary, he radically contested the very idea that one could achieve a transparent, direct and immediate knowledge of her own internal states. All knowledge is mediated by signs, even the knowledge of our internal dimension. This is the key assumption inspiring Peirce's long-standing externalism. With respect to the issue of anti-psychologism, Peirce's externalism suggests that 
knowledge of our internal psychological states is epistemologically irrelevant from a logical point of view.

4 Calcaterra (2006) acknowledges both the taxonomic explicit distinction between logic and psychology and the epistemological centrality of externalism. However, she recommends a reconsideration of Peirce's anti-psychologism. From her perspective, the externalist criterion must be left untouched. While psychology deals with how the mind works internally, logic focuses on external, publicly observable signs. But Peirce's externalist arguments against psychologism lead to a specific viewpoint, which must be distinguished from Kant's standard version of antypsychologism.

Kant's assumption of the independence of logic from psychology leads to the acknowledgment of a trascendental level, in which the necessary rules of thought must be situated. In contrast, Peirce's externalism brings about a distinction between logic and psychology, which must always be framed in accordance with the fundamental principle of continuity, which he calls synechism. Once we give up with the introspectionist paradigm, we must admit that psychological sciences as well aim at discovering the functioning of the mind by means of signs. Therefore, any distinction between psychology as a science of introspection and logic as a science which analyzes the relation between external signs proves to be meaningless, rather than false. It is meaningless because introspection is in itself impossible, if by introspection we mean immediate and epistemologically ideal access to internal states. The mind as well is made of signs, and therefore also the knowledge of the mind, even of its internal side, is mediated by signs. Once we acknowledge this semiotic continuity, a functional distinction between logic and psychology will substitute for an ontological or epistemological one:

Synechism does not certainly imply a denial of such distinctions; it rather suggests to look upon these distinctions as functional aspects of human existence, namely as different and yet "substantially" contiguous features of an evolving reality, or as signs of its own factual complexity. On the other hand, there is no sign which cannot be included in the process of reasoning, thus acquiring an "objective" meaning which also entails a self-controlled selection of the "pragmatic" and intellectual implications as connected with whatsoever acknowledgement of objectivity. (Calcaterra 2006: 44; original emphasis)

When understood in a strong ontological and epistemological sense, psychologism and anti-psychologism represent two answers to a single, impossible problem: that of clearly defining the boundaries between logic and psychology, either by drastically and substantially separating the two domains - anti-psychologism - or by conflating the former into the latter - psychologism. Peirce's antipsychologism does not blur the distinction between logic and psychology. Rather, it shows how this distinction cannot be grounded on the externalism vs. internalism dichotomy. This would be impossible, insofar as nothing like a purely introspectionist psychological science exists:

I have long ago come to be guided by this maxim: that as long as it is practically certain that we cannot directly, nor with much accuracy even indirectly, observe what passes in the consciousness of any other person, while it is far from certain that we can do so ( and accurately record what [we] can even links at best but very glibberly) even in the case of what should through our own mind, it is much safer to define all mental characters as far as possible in terms of their outward manifestations. (EP2 465)

7 The former quote apparently suggests the idea that a Peircean treatment of psychology should be an intrinsically anti-psychologist one. But these ironic words should not be 
taken too literally. Refusal of the introspectionist paradigm in psychology does not lead to the reduction of psychology to a kind of purely behavioristic semiotics. Such a misunderstanding could arise from the fallacious identification of antiintrospectionism with the denial of the existence of internal psychological states.

It is true that the pragmatist battle against introspectionism led by authors like Peirce and George Herbert Mead entails the refusal of inner knowledge as an immediate, transparent and epistemologically flawless relation between oneself and her own internal mental states. This standpoint could be be superficially equated with a watsonian form of behaviorism, denying the very existence of mental and psychological states. But this is not the case for pragmatist authors. For both Peirce and Mead, anti-introspectionism does not entail repudiating the existence of internal psychological states. ${ }^{1}$ Rather, it simply implies that the knowledge and the expression of such states is always mediated, or embodied, by communication. This involves a clear epistemological assumption: differently from logic, defined as the formal doctrine of signs, psychology is able to study internal states, on the condition that this inquiry be focused on the communicative processes through which these internal states are expressed and conveyed.

9 A Peircean version of anti-psychologism is therefore disinclined to reductionism in two senses. It opposes the reduction of logical to psychological processes. Moreover, it opposes a behaviorist-like reduction of psychology to the simple observation of external behaviors, and the consequent eliminativism. Thus, such a version of antipsychologism implies a communicative and semiotic continuity between logic and psychology. At the same time, it encourages a functional distinction between these two domains. Logic consists of a formal doctrine of the connection of external signs. Psychology deals with psychological processes by refusing the criteria of introspectionism - the very idea of a flawless and immediate epistemological acces to the internal sphere of experience. At the same time, it considers the focus on internal psychological states as an inescapable part of psychological inquiry. The focus on communicative processes, therefore, does not rule out the importance of internal states. $^{2}$

In her 2006 article, Calcaterra argues that a Peircean version of anti-psychologism involves neither a dismissal of the internal dimension of experience, nor the consequent reduction of psychology to a kind of behavioral and behaviorist semiotic. On the contrary, Peirce acknowledges that the inner aspect of sensations and emotions refers to the "costitution of the mind" (CP 5.291). At the same time, he deems as equally false the idea according to which sensations and emotion belong exclusively to the inner dimension. Peirce believes that sensations and emotions involve a relation with the external world. As soon as emotions and sensations are expressed - e.g. by saying "I am sad," "I am angry," these allegedly purely internal states become "interconnected with the social cognitive and value-related criteria shaping the 'external' frame of individual life" (Calcaterra 2006: 38). This twofold acknowledgement of the psychological importance of internal states, and of the necessity of a communicative approach to their expression, establishes both the autonomy of psychology from logic, understood as the formal doctrine of external signs, and the continuity of these two discipines into the general communicative and semiotic framework. Therefore, rather than assuming an eliminativist standpoint with regards to self-related phenomena, ${ }^{3}$ Peirce seems to encourage a study of psychological processes based on semiotics. 
11 In this paper, I would not move from a Peircean standpoint in order to discuss the persistence of psychological processes in logical processes. Rather, my inquiry moves in the opposite direction. Specifically, I intend to employ Peirce's semiotic tools in order to inquire into the logic of psychological processes. This last statement could puzzle the reader. How could a semiotic inquiry into psychology have a logical import? Did not Peirce draw a clear distinction between logic and semiotics? Wouldn't we be better off making a previous methodological decision by choosing between logical and semiotic approaches to psychology?

12 Despite the apparent contradiction, from a Peircean standpoint it makes perfect sense to maintain that a semiotic account involves, to a certain degree, a logical account as well. As Peirce clearly stated, logic, understood "in its general sense," is "only another name for semiotic, the quasi necessary, or formal, doctrine of signs" (CP 2.227). Therefore, a psychological account could be provided with logical and semiotic relevance, as long as we acknowledge that what is relevant to both logic and to semiotics is "the thought embodied in some communicable form such that it might be made a focal object of critical assessment. In other words, what is salient is the symbolization of thought" (Colapietro 2003: 165-6). Following this logic, attention will be focused on signs and communicative practices, rather than on the introspective realm of internal representations.

Bearing Peirce's version of anti-psychologism in mind, I will focus on psychological processes understood as communicative processes. This approach is not without precedent. Communication has been a key issue in psychology ever since Sigmund Freud wrote his first articles. Despite considering the unconscious as non-liguistic, Freud acknowledged the key role played by language in psychoanalytic therapy. Therapy seems then to happen through language and by means of language. As witnessed by the familiar case of Anna O.'s therapy, psychoanalysis consists in a "talking cure" (Breuer \& Freud 1895/1995). Several decades later, and from a totally different perspective, Paul Watzlawick and his research group in Palo Alto developed a radical psychological constructivisim, based on the essential role of communicative exchanges (Watzlawick, Beavin \& Jackson 1967). These are just two examples of how the role of communicative processes has been of great importance for psychological theory, in all its complexity and in all its varieties.

In this article, I will use Peirce's approach to communication and semiosis in order to discuss the outcomes and the categories of a specific psychological theory, in this case, attachment theory. In the second part, I will discuss the historical antecedent attempts at inquiring into psychological processes in a semiotic way. In the third part, I will employ Giovanni Maddalena's Peircean distinction between complete and incomplete gestures as a tool for psychological inquiry. In the third part I will discuss the theoretical framework of attachment theory, focusing specifically on the distinction between secure, dismissing and preoccupied attachment patterns. By presenting and discussing different measurements of attachment, such as the Adult Attachment Interview (AAI, George, Kaplan \& Main 1985/96), the Adult Attachment Projection (AAP, George \& West 2006), and the Patient Attachment Coding System (PACS, Talia, Miller-Bottome \& Daniel 2015), in parts 4, 5 and 6 I will try to show how these distinctions can be accounted for by means of Maddalena's classification of gestures as complete and incomplete. This distinction depends on the different kinds of blending between the three semiotic elements - icon, index, symbol - and the three 
phenomenological categories - firstness, secondness, thirdness - that a gesture embodies. While dismissing and preoccupied attachment patterns seem to be characterized by the performance of different kinds of incomplete gestures, secure individuals appear to be able to express themselves by means of gestures provided with a higher degree of completeness. This discussion shows a clear connection between the semiotic and phenomenological category of completeness, and the psychological category of security. The normative import of this connection will be briefly discussed in the conclusions (part 7). ${ }^{4}$

\section{A Semiotic Reading of Psychology? Historical Antecedents}

In the recent decades, different authors have been attempting to read psychological processes by selecting between a semiotic or a pragmatic approach. Both of these approaches have been pursued in relation to psychoanalytic theory. From a semiotic standpoint, a reference to Lacan is unavoidable. In his original development of Freudian psychoanalysis, Lacan apparently overturned one of the key assumptions of his master. While Freud explicitly stated that unconscious representations are not linguistic, Lacan maintained that the unconscious is structured like a language. Although this statement does not mean that the unconscious is linguistic (Cimatti 2015), it is undeniable that Lacan opened the door to a semiotic reading of psychoanalyis. Lacanian psychoanalysis was based on the French tradition of semiosis started by Fernand de Saussure, and on the work of the Czech linguist Roman Jakobson.

On the pragmatic side, one could recall Alfred Lorenzer's proposal. In some ways, the work of Lorenzer is in accordance with Freud's fundamental hypotheses. Specifically, he maintained that psychotherapy has to deal with unconscious behaviors which cannot be fully conceived as linguistic. But in contrast to Freud, he refused to conceive the distinction between the linguistic and conscious dimension and the non linguistic unconscious dimension in dichotomic terms. As an alternative, he proposed to distinguish between symbols - that is, linguistic expressions - and stereotypes.

While symbols can also be employed outside a specific and concrete context, stereotypes may act only inside a specific dramatic setting. Also, in contrast to symbols, stereotypes make any separation between subject and object impossible. This impossibility has crucial consequences. The separation of the subject from the object leaves room for the intervention of reflexive thought. By reflecting, the subject can select his possible responses to a certain object. In this way, symbols can be transformed and adapted to the changes of the social and relational context. ${ }^{5}$ On the contrary, stereotypes force the individual into a net of repetitions and automatisms. This behavior is fixed and rigid, and it cannot be adapted to the varying social environment. As long as they continue to produce unbearable conflicts, some contents are de-symbolized: they disappear from consciousness, but continue acting as repetitive uncontrollable patterns within a specific scene, that is, within a specific interactional environment.

Thus there is a wide array of writing which attempts to apply either semiotics or pragmatism in the study of psychology and psychoanalysis. Authors who elect to integrate both semiotic and pragmatic approaches in the same work have been far 
more sporadic. Some authors (Santaella 1986; Nordtug 2004; Santarelli 2013) have tried to bring together Lacan and lines of reasoning based on pragmatist authors such as Mead and Peirce. Perhaps the most systematic attempt at reading psychoanalysis pragmatically through the lens of a pragmatic semiotics has been pursued by Vincent Colapietro. In a series of articles, Colapietro discusses psychoanalytic issues by employing Peircean theoretical tools. One of the most interesting outcomes of these discussions is the concept of the logical quasi-final interpretant. Debating with the philosopher Teresa de Lauretis (2000), Colapietro originally defines that logical quasifinal interpretant as an interpretant which, despite producing a habit, obstructs any critical reflection and reconstruction of the habit itself. This kind of interpretant is exemplified by neurotic habits, a typical case of habits provided with generality, but resistant against any habit change driven by self reflection. Similarly to the stereotypical unconscious processes defined by Lorenzer, logical quasi-final interpretants are defined by Colapietro as:

Any habit that would arrest or, worse, destroy opportunities for cultivating deliberately formed, self-analyzing habits, but which would do so in its role as quasi-final interpretant, would have a very important status within the economy of our psychic lives. (Colapietro 2000: 146)

19 The approach followed in this paper is undoubtedly sympathetic to that proposed by Colapietro. The idea according to which both conscious and unconscious processes can be dealt with in a semiotic and pragmatic way is one of the key theses of the present paper. By moving from this Peircean background, I will discuss the possibility of reading the existing classification of attachment patterns in a semiotic way. In doing this, I will make use of conceptual tools provided by a recent book, written by another author inspired by Peirce.

\section{Giovanni Maddalena's Peircean Theory of Gestures}

In his book The Philosophy of Gesture, Maddalena defines gesture as "any performed act with a beginning and an end that carries a meaning (from gero = I bear, I carry on)" (Maddalena 2015: 69-70). In accordance with Peirce's pragmatic maxim, meaning is defined as "the cluster of conceivable effects of an experience" (70).

Gestures can be classified as complete and incomplete. Maddalena defines complete gestures both in a semiotic and in a phenomenological way. From a semiotic point of view, a complete gesture unites all three semiotic elements: Icons - "signs that represent their objects by similarity" -; indexes - "signs that represent their object by direct contiguity or brute force" -; symbols - "signs that represent their object by interpretation" (Maddalena 2015: 20).

From a phenomenological point of view, a complete gesture consists in the equal blending of Peirce's phenomenological categories: firstness, secondness and thirdness. ${ }^{6}$ Peirce defines firstness as the quality "of feeling, or of mere appearance [...] the quality itself, independently of its being perceived or remebered, is an example" (CP 8.328). It is the "flavor sui generis" (1.531) of experience, the qualitatively connotated novelty which cannot be temporarily labelled into a pre-existing schema. Secondness is "the element of struggle" (1.322), "the experience of effort" which "cannot exist without the experience of resistance" (8.330). It is the dimension of occurrence, of something actually occuring and therefore involving "forceful relations of action and reaction" 
(Short 2007: 78). Finally, thirdness is the element of generality: "The third element of the phenomenon [...] that we perceive it to be intelligible, that is, to be subject to a law, or capable of being represented by a general sign or Symbol" (8.268). On account of its lawful nature, thirdness imparts "a quality to reactions in the future" (1.343).

The balanced blending of the three semiotic and phenomenological categories involves some specific features. A complete gesture must then be creative, insofar as it embodies the iconicity of possible forms and feelings; it must be unrepeatable, insofar as it embodies the singularity of indexicality; it must be finally recognizable, insofar as it is expression of a general regularity, which could be publicly acknowledged. In this way, a complete gesture is one which is able to synthesize, and which makes possible the development from an original vagueness to the generality of consequences by means of a concrete act. By means of a complete gesture we can act, communicate, understand and learn at the same time.

Conversely, incomplete gestures can be defined as those gestures in which at least one of the three categories is weak - and even if they are never completely lacking. This opens the path to a classification of incomplete gestures, according to the different combination of the three categories or elements that these gesture could embody. A gesture provided with thirdness, but poor in firstness and secondness, is labeled as abstraction or generalization. Gestures scarcely provided with firstness, but structured by a blending of secondness and thirdness, are called by Maddalena schematizations, or stereotypizations. This is the case of "a habit without novelty, a habit in Wittgenstein's sense of the word (like driving a car when one has long ago learned how)" (Maddalena 2015: 75). In both cases, firstness and iconicity is almost lacking. This means that schematizations and abstractions somehow hinder the emergence of novelty, understood as something qualitatively connotated which cannot be immediately catalogued in the existing schema and concepts. More generally, incompleteness derives from a blending of the three different semiotic semiotic elements or phenomenological categories, in which at least one of the three is weakly present, even if never completely missing.

I can now introduce the key hypothesis of this paper: the various kinds of attachment patterns can be traced back to the different kinds of gestures which are usually displayed by individuals. These gestures can be successfully classified by means of Maddalena's distinction between complete and incomplete gesture, and by the consequent taxonomy of incomplete gestures. This hypothesis requires of course a small review of attachment theory, which will focus on the different ways in which these different attachment patterns have been classified.

\section{Defining and Measuring Attachment}

The concepts of security and insecurity are two key concepts in attachment theory. Attachment theory has been used by theorists to understand how the early experience of care with parental figures fosters security. The field of attachment theory has developed starting from John Bowlby's theory, according to which human beings develop an "attachment behavioral system having primary and immediate responsibility for regulating infant safety and survival in the environment of evolutionary adaptedness" (Main 1996: 237). Moving from Bowlby's insights (Bowlby 1969/82), Mary Ainsworth catalogued four different ways of reacting to the so-called 
"Strange Situation" (Ainsworth, Blehar, Waters \& Wall 1978). Strange Situation consists of a laboratory procedure, in which the child is observed while a stranger and a caregiver enter and leave his room. These movements create different situations separation from the caregiver; being alone with a stranger; reunion with the caregiver, and so on. According to the different reactions to these potentially stressful situations, Ainsworth labelled the attachment behavior of the observed children under four different categories. The secure child explicitly shows that she/he is missing the caregiver during the separation. Shortly after the reunion, the secure child returns to actively interact with the parent. The avoidant child does not cry during separation, she does not appear emotionally moved. When the parent comes back, the avoidant child ignores him or her. The resistant/ambivalent child appears as preoccupied with the parent during the whole procedure. He/she shows either angry or passive behavior, and he/she is not able to play with the caregiver after the reunion. Finally, the disorganized child may show disorganized behaviors - es. trance expressions - in the presence of the parents. His/her behavior may also significantly overlap with the other three categories.

The Adult Attachment Interview (AAI) (George, Kaplan, \& Main 1985/96) is one of the most significant developments in attachment research. While the Strange Situation classifed attachment partners in children, AAI codes attachment related systems of representations in adults. The AAI is a 1 hour long interview, in which "participants are asked for descriptions and evaluations of childhood attachment relationships, loss of attachment figures, separations from attachment figures, and the effects of these experiences on the participant's development and personality" (Main 1996: 240). By analyzing the verbatim trascription, four different kinds of adult attachment systems can detected. These four types of adult attachment explicitly reflect the four different kinds of infant attachment identified by the Strange Situation.

With respect to attachment, a secure-autonomous adult will be able to present life experiences in a clear and coherent way. An adult will be classified as dismissing when positive evaluation of parents are not supported, or contradicted, by concrete examples, or when negative experiences are downplayed. Transcripts of dismissing adults are normally short. The preoccupied type displays angryness and confusion when talking about his/her life experiences. Responses are usually long, and sometimes irrelevant to the topic of discussion. Finally, the unresolved-disorganized adult shows striking lapses in the monitoring of reasoning or discourse when talking about abuses or losses.

Being based on the analysis of verbatim trascriptions, the AAI strongly emphasizes the role of discourse and language in achieving the four different kinds of classifications. Specifically, a great role is played by the violations of Paul Grice's four conversational maxisms: quality, quantity, relation and manner. For instance, as showed by their unusually long trascriptions, preoccupied adults regularly violate the maxim of quantity, insofar as they do not present and evaluate their life experiences in a succint way, as required by Grice's maxim. But the central role of language in the real of experiments such as these is no longer valid in a theoretical context. According to Main, differences in overt linguistic behavior reflect deeper differences in "states of mind with respect to attachment" (Main 1993). Speech acts and comunication are the superficial outcome of the deeper and determining level of internal representations. 
full scope of attachment research is a vast subject, which cannot be adequately treated here. However, there is a surprising fact that deserves attention. During the last decades, attachment scholars have increasingly stressed the importance of the level of mental representation. But at the same time, processes of measurement and classification of attachment have increasingly focused on language and semiotic processes. An increasingly mentalistic conception of attachment processes has thus been developing simultaneously with an increasing focus on linguistic and semiotic behaviors as signs of attachment. This increasing focus on the communicative dimension seems to encourage our attempt to analyze attachment theory from a Peircean standpoint. If linguistic - and therefore semiotic - behavior is the crucial domain of psychological observation, it follows that a semiotic approach in this regard will be at least legitimate. The two following examples seem to confirm these optimistic predictions.

\section{The Adult Attachment Projective: Complete and Incomplete Narrations}

The Adult Attachment Projective (AAP, George \& West 2006) is an adult attachment classification system based on the analysis of individuals' responses to a set of seven attachment-related drawings. These drawings are selected from pictures drawn from children's literature, psychology textbooks, and photography anthologies. The AAP drawings depict events that, according to theory, activate attachment; for example, illness, solitude, separation, and abuse (George \& West 2001: 32). The participants in the test are asked to tell a story elicited by the drawing. Working on the verbatim trascriptions of the narrated story, the adults are classified according to the four AAI categories: secure, dismissing, preoccupied and unresolved.

These classifications and the way they are achieved could be accounted by means of a gestural approach. The participant in the AAP test are asked to produce semiotic gestures - i.e. narrations - in order to semiotically develop other gestures - the drawings. But even more surprisingly, these different classifications can be accounted as different degrees and varieties of incompleteness and completeness. ${ }^{7}$ In order to prove this point, I will now present and briefly discuss three excerpts taken form the examples of narrations classified as dismissing, preoccupied and secure attachment provided by George and West. These narrations have been elicited by the projective picture named "bed" (fig. 1). 
Figure 1. AAP projective picture: Bed

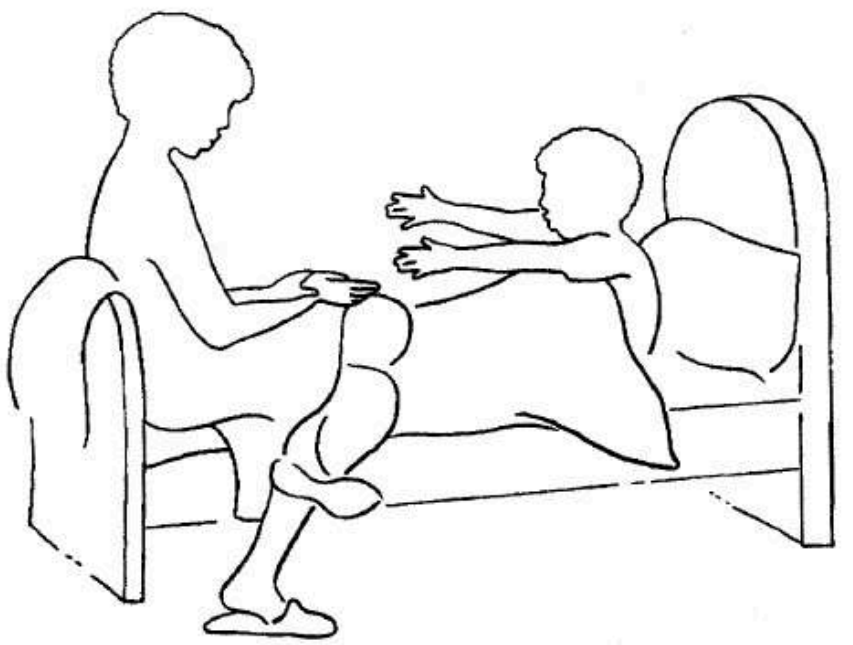

Figure 1 AAP projective picture: Bed

Dismissing Attachment. Um, for some reason I think these two people are black because they have frizzy hair. This is a mom and her son on a bed. The son is reaching for the mom and the mom is not really reaching back for some reason. And I'm not sure if it's a cultural or just if it's personal but she's wearing slippers. [...] Well the child is uh needy, is looking needy and the mom is sort of half there, half not there. She's probably giving as much as she can give these days just doesn't know what to do. Um, but she seems relaxed, the way her hands are folded and her knees are crossed. (George \& West 2001: 37)

On the level of the relation between the narrator and the narrated story, there are no interferences. As George and West explain, "dismissing individuals rarely wander off track (relation violation); they do not blur self - other boundaries during the storytelling process and, thus, personal experience references are absent" (George \& West 2001: 51). Therefore, secondness can be easily detected. On the contrary, firstness is scarcely present. There is no hint of feeling. There is a clear need of labelling the drawing into general categories - es. Black people, the cultural reason of wearing slippers - but no hint of emotionality and feeling. "Descriptions of sensitive, reciprocal interaction are typically absent in their story content. Instead, dyadic interaction may appear to follow a social script or cultural rule that dictates how people should behave in a particular context" (George \& West 2001: 49). Even when the dismissing individual indicates the self states of the characters of the narration and of the drawings - e.g. the child is "needy" and the mother is "relaxed" - she or he usually portrays the characters as involved in instrumental actions that do not involve or modify anyone's subjective experience (Talia 2016).

Preoccupied Attachment. Well this one it seems like it's sad. Um the child is sick or hurt or something and he's reaching out and I can't tell if the mother's got something in her hands wanting to - or you know she's giving it to him - about to give it to him or whether she's just reaching her hands out, but she looks reserved, kind-of held back - like she's not leaning forward to him. [...] Also reminds me of when my husband was sick too. Yeah. Um I'd definitely see that this is being my husband and you know this being me because that was really frustrating with him being unable to communicate - I didn't feel there was anything I could do - I couldn't understand what he wanted, there was no way to find out what he wanted. (George \& West 2001: 38) 
Firstness is present since the first line - the child "seems like it is sad." At the level of the relation between the narrator and the narrated history, something happens at the half of the narration. Particularly, the boundaries between the narrator's story and the narrated story blur. The narrator starts talking about the problems between her and her husband. Lacking these boundaries, the story looses its character of actual occurrence, that is, its secondness.

The invasion, so to speak, of self-references as part of the narrative suggests that the individual is being overwhelmed by his or her attachment stress; that is, they indicate that representational merging or self-absorption is overwhelming attention to the AAP picture as an external stimulus. (40)

In more recent projective experiments, this lack of boundaries plays a less decisive role in the preoccupied narrations. However, scarceness of secondness easily reappears at the level of the relations between the characters of the narration. In semi-projective measures, preoccupied subjects often tell stories in which one of the characters obstructs the other's response (e.g., a pictured child runs after the parents and then shoots them, Kaplan 1987), or of the interviewer (e.g. the speaker loses track of the task and begins discussing unrelated topics, George \& West 2006). The preoccupied storytelling then involves strategies in which one of the characters explicitly displays his feelings (firstness), and at the same time is actively engaged in discouraging and undermining the actual occurrences of the responses and contributions of the other (weak secondness).

Secure Attachment. [...] well this looks like bedtime and mum has just sat down to - say goodnight and - this young fellow feels he needs a hug before he goes to sleep - so she slides up a little closer to him an gives him a big hug - and ahh strokes his head, his back and then tells him to roll over onto his tummy and she'll give him a bit of a massage - and that calms him down an' - gets him ready for sleep and she kisses him good-night - and leaves the room. (George \& West 2001: 34)

The dimension of feeling is explicitly mentioned - "this young fellow feels he needs a hug before he goes to sleep." Secondness is present as well, since this story is explicitly separated from the life of the narrator. The narrator seems to be involved somehow, but still the boundaries between his story and the narrated story are explicit. The story is also clearly costructed and organized. In a word, there is connectedness and continuity, and therefore, thirdness. By means of such a gesture, the narrator recognizes the fact that the drawing depicts an attachment-relevant situation: "The hallmark of security in the AAP is the demonstration of the ability to draw upon attachment to remedy distress consequent to the activation of the attachment system by the picture scenes" (48). And thus we have a complete gestures as defined by Maddalena. The story recognizes attachment by drawing a gesture - in this case, a narrative - which displays attachment.

The distinction between secure and insecure (dismissing and preoccupied) attachment, as detected in the different "completing" stories, apparently consists in the presence of gestures embodying different kinds and degrees of completeness and incompleteness. Dismissing stories are evidently poor in firstness. By following Maddalena's classification, they could be labelled under the category of schematization. The very name of this category expresses in a meaningful way the dismissing subject's attempt to downplay the "quality" of the narration and the singular quality of the experiences of the characters, by directing them into general and social categories and schema the mum and the child "should be black," and she wears slippers for cultural reasons. 
Preoccupied-subject narrations are on the contrary provided with firstness, but poor in secondness. The incapacity of setting boundaries between the narrated story and the narrator's own story is well accounted for by the category of "projection" (firstness and thirdness, scarce secondness), that is, an "action that plans or models or fosters further relationships without the actual happening of their occurrence" (Maddalena 2015: 77). The same process can be seen operating in the interactions between the characters of the story. Relationships in this case are shaped by one character's actions obstructing the other character's actions. This obstruction can take two forms: in some cases it prevents the very physical occurence of this action, at other times its it simply blocks the action from having meaningful consequences. projective-preoccupied narrations and of schematizing-dismissing ones. They are poor neither in secondness, nor in firstness. They are well constructed, well connected and coherent narrations, in which the firstness of feeling emerges without blurring the specificity of the narrated story, and its separation from the personal experience of the narrator. The characters of the narration express their feelings, and they are open to the contributions of the other characters.

To sum up, differences in attachment as they emerge from the narratives of the AAP can be easily and completely described in terms of complete and incomplete gestures. These differences, therefore, appear as semiotic and communicative differences. According to both Main and George, these linguistic signs refer to a cognitive internal object, that is, the system of internal representations. People communicate in different ways because their systems of internal representation are different. Recently, this presumed need for an internal representational difference as the explanation for differences in communication and in attachment has been challenged.

\section{A Radical Move to Communication. The Patient Attachment Coding System}

41 The connection between completeness and security; the isomorphism between different kinds of insecure attachment patterns and different kinds of incomplete gestures: these analogies are even more stunning once we acknowledge that they can also be singled out in a more recent theoretical attempt. In his 2015 paper, Alessandro Talia et al. tried to radicalize the linguistic turn implicitly inaugurated by Main and George. Both AAI and AAP are empirically focused on linguistic speech acts. At the same time, they consider these communicative behaviors as signs of an underlying internal set of representations, which structure both the linguistic behavior and the attachment pattern of the individual. On the contrary, Alessandro Talia's Patient Attachment Coding System (PACS, Talia, Miller-Bottome \& Daniel 2015) endorses a more radical semiotic and communicative approach, by focusing on the qualities and the characters of speech and language without requiring the mediating function of internal representations. Talia et al. do not believe that internal representations shape our ways of communicating a priori. Rather, they endorse the pragmatist viewpoint according to which people understand their experiences, either internal or external, by communicating them. 

based on any session of psychotherapy. Specifically, sessions of psychotherapy are recorded and transcribed, and the linguistic expressions and behaviors of the patient are analyzed by means of markers. These markers are catalogued and analyzed according to four scales: Proximity-Seeking Contact-maintaining scales, which comprise markers that actively elicit or encourage attunement; the Avoidance scale, which comprises markers that shift the attention away from clients' ongoing experience and avoid the direct elicitation of attunement; and the Resistance scale, which comprises markers that prevent the therapist from expressing a different point of view, thereby impeding any less than perfect attunement (Talia et al. 2015: 8). The ratings attained in these scales are employed as means to classify the different kinds of attachment patterns.

issing individuals normally obtain high levels on avoidance scale, associated with an evasion of the therapist's inquiries into patients's positive and negative experience, and a minimization of the patient's mental states regarding this subject. What is interesting, is that these strategies seem to apply not only to stressing situations, but to positive experiences as well. In Peircean terms: these strategies involve avoidance of firstness in general, whatever the connotation of this firstness is. This avoidance is clearly represented by the strategies of generalization, often employed by dismissing patients. Let us take an example form everyday life. Someone asks me: "How do you feel after breaking up with your girlfriend?," and I answer "I feel like anyone in my own situation would." My generalizing gesture is an instance of "schematization," that is a gesture poor in firstness but not in secondness and thirdness. This gesture allows the avoidance of the direct expression of feeling, by including the actual occurrence of the event in a general pattern, without expressing what Peirce would call the "flavor" of my experience (CP 1.531).

Preoccupied score high with the resistance scale. This scale tracks the attempts in enlisting the therapist's agreement with the patient's views, and the disregard and the limitation of the therapist's contributions. Preoccupied patients are then actively involved in limiting and even in denying the "secondness" of the contribution of the therapist:

Whenever they [dismissing individuals] express their experience, they tend to do so in a way that restricts independent contribution from the therapist - for example, they quote themselves verbatim instead of describing their experience from a present perspective. Finally, whenever the therapist attempts to reflect the experience of the patient, the patient reacts as if she did not hear what the therapist said. (Talia 2016: 23)

On the contrary, the secure patient directly express her thoughts, is able to reflect on them and to negotiate them with the others, by taking into account their contributions to the conversation. Security is then matched once again with increasingly complete gestures, showing more balanced blend of the three semiotic elements and the three phenomenological categories. A completeness that, by the way, seems to express a reflexive habit of thought similar to what Colapietro pointed at in distinguishing between quasi final and final logical interpretants. We will briefly discuss the connection between completeness, security and rexflexivity in the conclusions.

The validity and the aptness of a semiotic reading of the classification of the different patterns of attachment seems to be reconfirmed. Dismissing individuals in the therapeutical context often produce incomplete gestures in the form of 
schematizations and generalizations. Preoccupied individuals gesturally express their inner feelings, but tend to strongly resist the contributions of the therapist. This resistance can be either direct - e.g. reacting as if they did not hear what the therapist said - or indirect - e.g. enlisting interpretations of their expressions provided by other people, in order to imply that the interpretations of the therapist are superfluous. Finally, security is once again marked by the ability of producing gestures provided with a higher level of blending between the three phenomenological categories and the three semiotic elements, and therefore, a higher level of completeness.

\section{Conclusion: Security, Completeness and Normativity} classification of different kinds of incomplete gesture seem to be a promising way to account for differences in attachment. Such an account will be communicative and semiotic. This means that it deals with the way in which people communicate, rather than necessarily calling into account a hidden system of internal representations. Such a Peircean account appears consistent with recent developments in attachment research. on language and speech acts. At the same time, they consider language as a sort of external sign of an internal system of representation, and they consider this latter system as the real effective causal ground in determining differences in attachment. Starting from a move to the level of the relation, Talia and his colleagues have been moving towards a radicalization of the primacy of communication. Rather than considering the "external" level of language as the indirect expression of the internal structuring system of representations, they have increasingly focused on the way in which internal states are expressed and communicated. In this way, it is communicative habits which shape the internal states, rather than the other way around. Since, as pragmatists maintain, we understand through communication, there is no hidden inner process occurring before, or hidden behind communication, structuring our communications themselves. An avoidant communication of our internal states is made up of incomplete gestures poor in firstness and iconicity. A person who expresses and communicates her internal states in a dismissing way, will also tend to have an avoidant exprerience and understanding of her own internal states. This move to the level of communication appears particularly consistent with the Peircean account proposed in this paper. This focus on communicative and semiotic processes is the background of the continuity between logic and psychology. At the same time, this continuity does not eliminate or ignore mental states. Psychology deals, among other things, with internal states, focusing on the way in which these mental states are expressed, communicated and negotiated with the other persons. ${ }^{8}$

Lastly, I would like to briefly return to the opening issue concerning the relation between logic and psychology. I previously claimed that the present account of psychology could be framed into Peirce's original and functional anti-psychologism. Once we endorse Peirce's broad idea of logic as the study of the connections between signs, it follows that psychological processes - both conscious and unconscious - could be accounted for in a communicative, and therefore logically relevant way. They 
respectively embody different degrees and qualities of completeness or, to use Colapietro's terms, of finality. This could be a good example of Peirce's statement: "For in my opinion, excepting Metaphysics, there is no science that is more in need of the science of Logic than Psychology proper is" (EP2: 501). But following Calcaterra and Colapietro, it has been noticed that logic cannot be reduced to some kind of analysis of observed psychobiological habits. Rather, being a normative science, logic preserves its normativity. It should tell us "how to think," instead of simply describing "how we think."

In this paper, psychological differences in attachment have been connected to Maddalena's taxonomy of complete and incomplete gestures. Since these distinctions are both phenomenological and semiotic, they must have by hypotheses a certain logical import. In turn, logic involves normativity. This begs the following question: What is the normative import of this reading of attachment theory?

51 A partial answer to this difficult question could be sought by focusing on the connection between security and completeness. It has come to light how secure attachment is expressed by gestures embodying a higher degree of completeness, in comparison to the incomplete gestures characterizing dismissing and preoccupied attachment. Secure individuals usually communicate their internal states and their life experiences in a more direct, coeherent and open way. They are eager to express the firstness of their experience, without downplaying the communication of their feeling; they do not usually strategically discourage the contributions of the therapist in PACS they do not downplay secondness; their accounts are more coherently articulated and more consistent. They thus display a higher degree of continuity, in the Peircean sense of the term, and therefore a higher degree of thirdness. A connection between this higher degree of completeness and security thus emerges.

Now, it is equally clear how the concept of security in attachment psychology is provided with a clear normative import. Given their qualities, secure communications are a desirable condition for the development and the success of therapy. They open the path to a more constructive and productive communicative interaction between client and therapist. Some authors have placed so much importance on this aspect that they suggest that the development of secure attachment in infants should be a positive goal which society should be try to achieve. ${ }^{9}$ Without taking part in this discussion, it is hard to deny that secure attachment is a desirable end in the context of therapy (Holmes 2015). Although security does not imply absence of psychological problems in any way, such a condition is helpful for the sake of a productive communicative relation between client and therapist and for the development of therapy. Increasingly complete gestures are then normatively connoted in the therapeutic context. Contrary to what the commonsensical understanding of the term "completeness" may involve, complete gestures open new ways for communication, rather than closing them. And conversely, incomplete gestures characterizing insecure attachment lead to more difficult communication between patient and therapist.

Clients with a secure classification are able to elicit attunement and are open to the therapist's attempts to attune. As a consequence, they share their experience in an open and balanced way, which facilitates focused therapist interventions. These clients also demonstrate a willingness to take into account alternative perspectives and consider their own perspective as fallible, which may facilitate the emergence of mentalization (Fonagy, Gergely, Jurist, \& Target 2002). [...] Conversely, many of the markers of insecure in-session attachment seem to constitute obstacles to good 
therapeutic process. Namely, our observations suggest that avoidant patterns of attunement prevent an experientially grounded therapeutic dialogue, while preoccupied patterns seem to make it difficult for clients and therapists to maintain a consistent focus on the therapeutic tasks. (Talia et al. 2015)

The connection between security and completeness is therefore explictly connotated in a normative way, at least in the context of therapy. Secure individuals' capacity for balanced expression of their own experiences and recognition of their own "fallibilism" constitutes a desirable condition. Therefore, security is not only an observation-based description of how some people actually communicate, but also a suggestion about how people "should" communicate for the sake of therapy.

wike to conclude with a final consideration. Fonagy et al. (1991) showed how secure classifications in the AAI are related to the reflective function, that is the capacity to accurately indicate mental states underlying behavior in the self and the other. This means that, beside being connected with coherence, openness and fallibilism, security is also connected with the capacity of reflecting on mental states, and of considering mental states in the self and the other as the object of a further examination and scrutiny. The normative connection between security, completeness and reflexive capacity seems to be perfectly consistent with Colapietro's brilliant explanation of Peirce's view of logic both as a normative science and as a "particular species of morality":

We can mind what we say and infer. The critic of argument ultimately makes sense only in reference to our capacity to exert a critical, decisive measure of control over what we say and how we reason. Logic as the critic of argument, thus, implies a critic in the sense of a deliberative agent self-consciously assuming a critical stance towards the use of signs as instruments of inquiry. (Colapietro 2003: 158)

\section{BIBLIOGRAPHY}

AINSWORTH M. D. S., BLEHAR M. C., WATERS E., \& S. WALL, (1978), Patterns of Attachment: A Psychological Study of the Strange Situation, Hillsdale, NJ, Erlbaum.

BOWLBY J., (1969/82), Attachment and Loss. Volume I: Attachment, New York, NY, Basic Books.

BREUER J. \& S. FREUD, (1895/1995), Studies on Hysteria, in Strachey J. (ed.), The Standard Edition of the Complete Psychological Works of Sigmund Freud, London, Hogarth Press, vol. 2, 1-335.

Calcaterra R. M., (2006), "Psychology and Anti-Psychologism in Peirce," in Fabbrichesi R. \& Marietti S. (eds.), Semiotics and Philosophy in C. S. Peirce, Newcastle, Cambridge Scholar Press. CIMATTI F., (2015), Il taglio. Linguaggio e pulsione di morte, Roma, Quodlibet.

Colapietro V., (2000), "Further Consequences of a Singular Capacity," in J. Muller \& J. Brent (eds.), Peirce, Semiotics and Psychoanalysis, Baltimore and London, The John Hopkins University Press.

colapietro V., (2003), “The Space of Signs: C. S. Peirce's Critique of Psychologism," in D. Jaquette (ed.), Philosophy, Psychology \& Psychologism, Dordrecht-Boston-London, Kluwer Academic Publishers.

European Journal of Pragmatism and American Philosophy, IX-1 | 2017 
CRITTENDEN P. \& A. LANDINI, (2015), “Attachment Relationships as Semiotic Scaffolding Systems," Biosemiotics 8, 257-73.

De Lauretis T., (2000), “Gender, Body and Habit Change,” in Muller J. \& Brent J. (eds.), Peirce, Semiotics and Psychoanalysis, Baltimore and London, The John Hopkins University Press.

DE WAAL C., (2013), Peirce. A Guide for the Perplexed, London-New Dehli-New York-Sidney, Bloomsbury.

FONAGY P., GERGELY G., JURIST E. L., \& M. TARGET, (2002), Affect Regulation, Mentalization, and the Development of the Self, NewYork, NY, Other Press.

fonagy P., STEELE H., STEele M., MORAN G., \& A. HIGGiTT, (1991), “The Capacity for Understanding Mental States: The Reflective Self in Parent and Child and its Significance for Security of Attachment," Infant Mental Health Journal 62, 891-905.

GEORGE C., KAPLAN N., \& M. MAIN, (1985/96), Attachment Interview for Adults, unpublished manuscript, Berkeley, University of California.

GEORGE C. \& M. WEST, (2001), "The Development and Preliminary Validation of a New Measure of Adult Attachment: The Adult Attachment Projective," Attachment \& Human Development, 3 (1), 30-61

GEORGE C. \& M. WEST, (2006), The Adult Attachment Projective Picture System: Attachment. Theory and Assessment in Adults, New York, NY, Guilford Press.

HOLMES J., (2015), “Attachment Theory in Clinical Practice: A Personal Account,” British Journal of Psychotherapy, 31 (2), 208-28.

Hookway C., (2012), The Pragmatic Maxim. Essays on Peirce and Pragmatism, Oxford, Oxford University Press.

JOAS H., (1985), G. H. Mead. A Contemporary Re-Examination of His Thought, Cambridge, MA, Mit Press. KAPLAN N., (1987), “Internal Representations of Attachment in Six-Years-Olds," paper presented at the Biennial Meeting of the Society of Research in Child Development, retrieved online.

LORENZER A., (1995), Sprachzerstörung und Rekonstruktion. Vorarbeiten zu einer Metatheorie der Psychoanalyse, Frankfurt/Main, Suhrkamp

MADDALENA G., (2015), The Philosophy of Gesture, Montreal, McGill-Queens.

MAIN M., (1993), "Discourse, Prediction, and Recent Studies in Attachment: Implications for Psychoanalysis," Journal of the American Psychoanalytic Association 41S, 209-44.

MAIN M., (1996), "Introduction to the Special Section on Attachment and Psychopathology," Journal of Consulting and Clinical Psychology, 64 (2), 237-43.

MEAD G. H., (1934), Mind, Self, and Society, Chicago, University of Chicago Press.

MEINS E., (2017), “Overrated: The Predictive Power of Attachment,” The Psychologist... retrieved online: [thepsychologist.bps.org.uk/volume-30/january-2017/overrated-predictive-powerattachment].

NORDTUG B., (2004), "Subjectivity as an Unlimited Semiosis: Lacan and Peirce," Studies in Philosophy and Education, 23 (2), 87-102.

PEIRCE C. S., (1931-58), The Collected Papers of Charles Sanders Peirce, volumes 1-6, edited by Charles Hartshorne \& Paul Weiss, volumes 7 and 8, edited by Arthur W. Burks, Cambridge, MA, Belknap Press of Harvard University Press. Cited as CP 
PEIRCE C. S., (1998), Essential Peirce, volume 2, edited by Peirce Edition Project, Bloomington, IN, Indiana University Press. Cited as EP 2.

SANTAELLA L., (1986), “As três categorias peircianas e os três registros lacanianos," Cruzeiro Semiótico 4, 25-30.

SANTARELli M., (2013), "From the Others to the Other: A Psychoanalytical Reading of George Herbert Mead," in Burke T. \& Skowronski P. (eds.), George Herbert Mead in the Twenty-first Century, Lanham, Lexington Books.

SHORT T. L., (2007), Peirce's Theory of Signs, Cambridge, Cambridge University Press.

TALIA A., MILLER-BOtTOME M. \& S. I. F. DANIEL, (2015), “Assessing Attachment in Psychotherapy: Validation of the Patient Attachment Coding System (PACS)," Clinical Psychology and Psychotherapy.

TALIA A., (2016), "Re-conceptualizing Adult Attachment: An Attunement-based Theory of Individual Differences," unpublished manuscript.

WATZLAWick P., BEAVIN J. B. \& D. D. JACKSON, (1967), Pragmatics of Communication. A Study of Interactional Patterns, Pathologies, and Paradoxes, New York, London, W. W. Norton \& Company.

\section{NOTES}

1. On the impossibility of conceiving Mead as a behaviorist, see Joas 1985.

2. It is probable that such a reconstruction of the relationships between psychology and logic does not literally reflect Peirce's position in this respect. Such a gap could be explained also by referring to historical circumstances. Suffice to say that when Peirce was writing the kind of psychology which I will discuss in the paper - mainly, psychoanalysis and attachment theory neither of these fields had yet come into existance. At the same time, an anti-dichotomic distinction between logic and psychology is far from contradictory to Peirce's views.

3. Some authors have suggested that Peirce's externalism goes as far as to deny the existence of the self (see De Waal 2013). An opposite viewpoint has been proposed by Vincent Colapietro, whose 1989 book aims at reconstructing "Peirce's approach to the self." Its complexity - and at times its ambiguities - renders this debate a still living and fruitiful one.

4. The reader could be legitimately puzzled by the decisive role played by psychological literature in a philosophical paper discussing Peirce's anti-psychologism. I will address this confusion in the following way. These references cannot be avoided given the purpose of the paper: moving from Peirce's original and complex anti-psychologism in order to articulate a semiotic analysis of psychological categories. Even though such an analysis could have been pursued at a pure philosophical level, the decision to discuss psychological literature stems from the acknowledgment of scientific psychology as a legitimate and necessary source of knowledge with regards to psychological processes. Such an approach is in step with the anti-reductionist naturalistic approach characterizing pragmatism. I would like to thank one of the two anonymous reviewers for pointing out the need for making such a clarification.

5. In this regard, Lorenzer is extremely close to George Herbert Mead. See Mead 1934.

6. This reconstruction of Peirce's phenomenological categories follows T. L. Short's impressive reconstructive work in Short (2007, especially 75-84).

7. We leave aside the tricky epistemological case of the "unresolved."

8. For an alternative reading of attachment patterns as interpetants, see Crittenden \& Landini 2015.

9. This overly wide normative connotation of security has been criticized by Meins 2017 . 


\section{ABSTRACTS}

Peirce's anti-psychologism hinges on two main assumptions. First, logic and psychology belong to two separate disciplines - respectively, the normative sciences and the experimental sciences. Second, externalism must be understood as a crucial and inescapable epistemological criterion. The introspectionist illusion, according to which individuals have direct and epistemologically flawless access to their own internal states, should be dismissed. As Colapietro (2003) and Calcaterra (2006) observe, Peirce's standpoint is far different from the Kantian classical account of anti-psychologism. This original take on anti-psychologism leaves room for a functional distinction between logic and psychology, emerging from a semiotic and communicative continuity. This means that psychology, unlike logic as a formal doctrine of signs, will be epistemologically appropriate for dealing with internal psychological states, on the condition that this inquiry be focused on the communicative processes through which these internal states are expressed and conveyed.

Such a Peircean account of anti-psychologism forms the epistemological background of this paper. My goal is to show how Peirce's approach to communication and semiosis can be applied in order to discuss a specific psychological theory, in this case, attachment theory. Specifically, I propose employing Giovanni Maddalena's Peircean distinction between complete and incomplete gestures (Maddalena 2015) to account for the distinction between secure, dismissing and preoccupied attachment patterns. To this end, I will be discussing three different measurements of attachment: the Adult Attachment Interview (AAI, George, Kaplan \& Main 1985), the Adult Attachment Projection (AAP, George \& West 2006), and the Patient Attachment Coding System (PACS, Talia, Miller-Bottome \& Daniel 2015). Throughout this discussion, I will examine the connection between the semiotic and phenomenological category of completeness, and the psychological category of security. This connection involves an interesting normative import, which I briefly discuss in the conclusions.

\section{AUTHOR}

\section{MATTEO SANTARELLI}

Università del Molise

matteosantarelli1985[at]gmail.com 